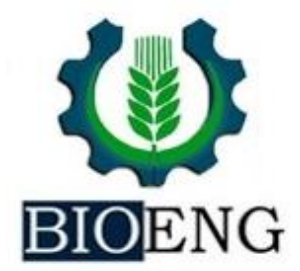

\title{
ÁCIDO-INDOL-3-BUTIRICO E ÉPOCA DE COLETA INFLUENCIANDO NO ENRAIZAMENTO DE Odontonema strictum (Nees) O. Kuntze
}

\author{
L. P. Mendonça ${ }^{1 *}$, J. N. Batista ${ }^{2}$, W. B. Magalhães ${ }^{3}$, J. P. Ferreira ${ }^{2}$, \\ C. A. Bucher ${ }^{2}$
}

${ }^{1}$ UNESP - Universidade Estadual Paulista, FCA, Campus de Botucatu, SP, Brasil.

${ }^{2}$ Universidade Federal Rural do Rio de Janeiro, Campus Seropédica, RJ, Brasil.

${ }^{3}$ Universidade Federal da Paraíba, Campus Bananeiras, PB, Brasil.

Article history: Received 25 April 2018; Received in revised form 10 June 2018; Accepted 14 June 2018; Available online 28 June 2018.

\section{RESUMO}

A Odontonema strictum (Nees) é originária da América central, pertence à família Acanthaceae e tem sua importância no uso como planta ornamental. Logo, tornam-se necessários conhecimentos sobre sua propagação por estaquia. Todavia, são incipientes informações técnicas no que concernem as respostas vegetativas da espécie ao uso de fitorregularores e épocas de coleta. Assim, objetivou-se com este trabalho avaliar o efeito do ácido-indol-3-butírico (AIB) e da época de coleta no enraizamento de estacas de Odontonema strictum (Nees) O. Kuntze. Para tal, estacas herbáceas, semilenhosas e lenhosas foram tratadas ou não (controle) com AIB nas concentrações de 1000 e $2000 \mathrm{mg} . \mathrm{L}^{-1}$. Após o tratamento, realizou-se o enterrio das estacas em areia grossa. O experimento foi realizado em duas épocas distintas (verão/outono e inverno/primavera). As características avaliadas foram porcentagem de estacas enraizadas, sobrevivência de estacas, número de brotos por estaca, comprimento do maior broto e comprimento da maior raiz. Os resultados mostram que a espécie tem grande capacidade regenerativa e pode ser considerada como de fácil enraizamento, independente da aplicação do fitorregulador (AIB) e do tipo de estaca utilizada. A época Verão/Outono mostrou-se mais adequada para coleta de estacas, porém a espécie não apresenta dificuldade em ser propagada ao longo de todo o ano.

Palavras-chave: estaquia, fitorregulador, ornamentação.

\section{ACID-INDOL-3-BUTTIRY AND COLLECTION TIME INFLUENCING ON THE ROTATION OF Odontonema strictum (Nees) O. Kuntze}

\begin{abstract}
ABSTRATC
Odontonema strictum (Nees), which originates in Central America, belongs to the Acanthaceae family and is important in its use as an ornamental plant. Therefore, knowledge about its propagation by cutting is necessary. However, technical information regarding the vegetative responses of the species to the use of phytoregulars and collection seasons is incipient. The objective of this work was to evaluate the effect of indole-3-butyric acid (AIB) and the collection time on the rooting of cuttings of Odontonema strictum (Nees) O. Kuntze. For this, herbaceous, semi-hardwood and woody stakes were treated or not (control) with IBA at concentrations of 1000 and $2000 \mathrm{mg} . \mathrm{L}^{-1}$. After the treatment, the cuttings were buried in coarse sand. The experiment was carried out in two distinct seasons (summer/fall and winter/spring). The evaluated characteristics were percentage of rooted cuttings, survival of
\end{abstract}

\footnotetext{
*1pastoremendonca@gmail.com
} 
cuttings, number of shoots per cutting, length of the largest shoot and length of the largest root. The results show that the species has great regenerative capacity and can be considered as easy rooting, independent of the application of the phytogulator (AIB) and the type of cutting used. The summer/autumn season proved to be more suitable for collecting cuttings, but the species presents no difficulty in being propagated throughout the year.

Keywords: cutting, phytoregulator, ornamentation.

\section{INTRODUÇÃO}

A família Acanthaceae possui uma distribuição pantropical, ocorrendo no Brasil cerca de 39 gêneros e 447 espécies. Dentre as espécies que ocorrem no Brasil, quatro espécies pertencem ao gênero Odontonema (PROFICE, 2015). Odontonema strictum (Nees), é conhecida popularmente como Odontonema, sendo originária da América Central (ZUFFELLATO-RIBAS et al., 2005). É uma planta adaptada em clima tropical, que pode atingir de um a dois metros de altura. Caracteriza-se pelo hábito arbustivo, de porte ereto, ramificada, com folhas simples, decíduas, ovaladas-alongadas, bordos ondulados e venação pinada (LARCHER \& BOEGER, 2006), sendo adequado para plantios a pleno sol ou a meia-sombra, junto a muros ou isolada. Sua importância como espécie ornamental está apresentada por suas próprias características, como: inflorescências terminais firmes e vistosas, com numerosas flores pequenas, de coloração vermelha, muito durável, sendo considerada uma espécie ornamental de grande expressão no país.

A estaquia é um dos métodos de propagação vegetativa mais utilizada em plantas ornamentais, pois possibilita a uniformidade e qualidade das mudas pela clonagem de genótipos selecionados de plantas matrizes, além de eliminar $\mathrm{o}$ período de juvenilidade (HARTMANN et al., 2010; ZEM et al., 2015).

Assim, tornam-se imprescindíveis informações técnicas referentes a fatores que possam influenciar o processo de propagação, dentre eles o uso de fitorreguladores. Isso, porque para a formação de raízes adventícias em estacas, são necessários determinados níveis de reguladores de crescimento na planta, dentre as auxinas, citocininas e giberelinas, sendo que, as auxinas são as de maior interesse no enraizamento de estacas (FACHINELLO et al., 1995). Além disso, a resposta à espécie pode ser influenciada por diversos fatores, tais como tipo de estacas, época de coleta e concentração destas substâncias, que pode atuar como estimulador ou inibidor do desenvolvimento de raízes adventícias (XAVIER et al., 2013). De acordo com Amaral et al. (2012), o tratamento com auxina endógena para diversas espécies de plantas ornamentais, proporciona enraizamento, uniformidade e rapidez para formação de raízes adventícias.

Entre as auxinas mais usadas e conhecidas, têm-se o ácido 3-indolbutírico (AIB), ácido indolacético (AIA), ácido naftaleno acético (ANA) e 2,4diclorofenoxiacético (2,4-D) (BLAZICH, 1987). O ácido 3-indolbutírico (AIB) é amplamente empregado devido à sua menor mobilidade, fotossensibilidade $\mathrm{e}$ maior estabilidade química na planta (HARTMANN et al., 2011; ALVES et al., 2014). Estudos indicam que o AIB pode promover a formação de raízes em estacas, acelerar a iniciação radicular, aumentar número e qualidade de raízes produzidas e aumentar a uniformidade de enraizamento (FACHINELLO et al., 2005).

No momento de preparo das estacas a serem propagadas, é necessário verificar qual a porção do ramo que deve ser utilizada. Isso, porque estacas herbáceas que apresentam menor grau de lignificação em comparação as estacas lenhosas, apresentam maior potencial meristemático para o enraizamento (XAVIER et al., 2013). Sendo assim, a escolha adequada do 
tipo de estaca é um fator de grande importância para viabilizar a produção de mudas (SANTOS et al., 2014).

A atividade cambial e o nível endógeno de auxina (IAA) podem ser influenciados pela época do ano, sendo assim, o momento de coleta das estacas é um fator importante a ser considerado por refletir no enraizamento (NEGISHI et al., 2014). Para algumas espécies qualquer época do ano é favorável à retirada de estacas, no entanto, para outras, a melhor época é quando as plantas encontram-se em baixo metabolismo (dormência) ou quando apresentam crescimento ativo (HARTMANN et al., 2011).

Deste modo, para aumentar a taxa de enraizamento das estacas, é necessário que

\section{MATERIAL E MÉTODOS}

Os experimentos foram instalados em duas épocas distintas: época 1 (verão/outono) em cinco de fevereiro de 2013, e época 2 (inverno/primavera) em dezenove de junho de 2013, ambos em casa de vegetação no setor de Horticultura, localizado no campus da Universidade Federal Rural do Rio de Janeiro (UFRRJ), em Seropédica-RJ, (22 $46^{\prime} \mathrm{S}, 43^{\circ} 41^{\prime} \mathrm{O}$, e altitude de $33 \mathrm{~m}$ ), sendo o clima da região incluído como Aw de Köppen.

$\mathrm{O}$ delineamento experimental foi em blocos casualizados, com tratamentos em esquema fatorial triplo $2 \times 3 \times 3$, referentes às duas épocas do ano (EP): (verão/outono e inverno/primavera); três tipos de estacas (TE) (lenhosa, semilenhosas e herbáceas) e três concentrações de AIB (0, 1000 e 2000 $\left.\mathrm{mg} . \mathrm{L}^{-1}\right)$. Foram utilizadas três repetições e 10 estacas por parcela, perfazendo um total de 540 estacas.

As estacas utilizadas no experimento foram coletadas como estacas caulinares, oriundas de matrizes sadias e vigorosas de Odontonema strictum (Nees), localizadas no Jardim Botânico da UFRRJ. As estacas foram selecionadas em três tipos, sendo lenhosa, semilenhosas e herbáceas, preparadas com corte reto transversal na base e ápice, com tamanho de aproximadamente $15 \mathrm{~cm}$ de comprimento, seja determinada a melhor concentração do fitorregulador utilizado (LAFETÁ et al., 2016), a melhor época para a retirada dos ramos para cada espécie (HARTMANN et al., 2011), e o tipo de estaca mais adequado de modo a viabilizar a produção de mudas (SANTOS et al., 2014). A hipótese é que o emprego do fitorregulador AIB, os diferentes tipos de estacas e a época de propagação influenciam no enraizamento de Odontonema strictum.

Assim, objetivou-se com este trabalho avaliar o efeito do AIB em diferentes tipos de estacas, e a época de retirada destas, visando à obtenção de estacas enraizadas e produção uniforme de mudas de Odontonema strictum (Nees).

não sendo mantidas folhas no ápice das estacas.

Após o preparo dos tipos de estacas, as mesmas foram transportadas para $o$ local do experimento e preparadas para a imersão com o fitorregulador.

O fitorregulador foi preparado a partir da solução de AIB, sendo utilizada uma solução estoque hidroalcoólica de ácido indol-3-butírico (AIB) na concentração de $20000 \mathrm{mg} . \mathrm{L}^{-1}(50 \% \mathrm{v} / \mathrm{v})$, para o preparo das soluções de trabalho com volume de $200 \mathrm{~mL}$, sendo estas com concentrações de $0 \mathrm{mg} . \mathrm{L}^{-1}(200 \mathrm{~mL}$ de água destilada), $1000 \mathrm{mg} . \mathrm{L}^{-1}(190 \mathrm{~mL}$ de água destilada $+10 \mathrm{~mL}$ solução estoque) e $2000 \mathrm{mg} . \mathrm{L}^{-1}$ de AIB $(180 \mathrm{~mL}$ de água destilada $+20 \mathrm{~mL}$ solução estoque).

As estacas foram imersas em solução de trabalho durante 10 segundos imediatamente antes do enterrio. Em seguida as estacas foram fixadas cerca de $1 / 3$ do seu comprimento em substrato de areia grossa previamente umedecida até a capacidade de campo. Durante o desenvolvimento das estacas, no ambiente interno utilizou-se a nebulização intermitente no intervalo de 30 minutos com 30 segundos de duração, com umidade relativa do ar próximo a sua saturação. 
As avaliações foram realizadas aos 57 dias após instalação do experimento, sendo avaliadas as seguintes características: porcentagem de estacas enraizadas (EE), sobrevivência de estacas (SE), número de brotos por estaca (NBE), comprimento do maior broto (CMB) e comprimento da maior raiz $(\mathrm{CMR}) \mathrm{em}$ centímetros.

Para a normalidade e homogeneidade das variâncias dos erros foram aplicados os

\section{RESULTADOS E DISCUSSÃO}

A porcentagem de estacas enraizadas (EE) não foi influenciada pelos fatores em estudos, com média de $100 \%$, demonstrando ser uma espécie de fácil enraizamento. A espécie apresenta alta capacidade de enraizamento, tal resultado corrobora com os dados obtidos por Zotelle \& Aoyama (2014) os quais obtiveram alto índice de enraizamento, comprovado com apenas $0,35 \%$ de mortalidade de estacas apicais e basais de Justicia wasshauseniana Profice (Acanthaceae) propagada sem a utilização de regulador vegetal. Zem et al. (2015) verificaram que a aplicação de diferentes concentrações de ácido indolbutírico (AIB) não influenciou no enraizamento de Drymis brasiliensis (Winteracea) cultivada nas quatro estações do ano. No presente trabalho, para estacas de Odontonema strictum (Nees) O. Kuntze, o tratamento controle já foi suficiente para o enraizamento das estacas, não havendo necessidade de adição do regulador vegetal, sendo assim, é considerada uma espécie de fácil enraizamento como a Psychotria nuda (NERY et al., 2014).

A formação de tecido cicatricial não foi detectada em nenhum tratamento em ambas as épocas avaliadas, corroborando com os resultados encontrados por Lima (2012) que estudando espécies da família Acanthaceae, encontrou baixa testes de Lilliefors e de Cochran \& Bartley, respectivamente. As características foram submetidas à análise de variância e, quando apresentaram diferenças significativas pelo teste $\mathrm{F}$, tiveram suas médias comparadas pelo teste de Tukey com $\alpha=5 \%$, e quando necessário efetuou-se desdobramento das variáveis para estudo dos efeitos de cada fator, utilizando-se o software Assistat versão 7.7 beta (SILVA, 2016).

porcentagem de estacas com formação de calo, sugerindo que os primórdios radiculares surgiram da região basal, indicando que a formação de raízes é independente da formação do calo. Do mesmo modo, Zottele \& Aoyama (2014) verificaram que os primórdios radiciais de Justicia wasshauseniana tiveram origem diretamente na região basal das estacas, não havendo formação de calos, com emissão de raízes independentemente do nó. A gênese de raízes adventícias pode ocorrer por dois processos distintos; o primeiro trata-se do desenvolvimento direto da raiz a partir dos tecidos caulinares e, o outro consiste num processo indireto, onde ocorre a formação de calos antecedendo a produção das raízes (ALTAMURA, 1996). Como não houve formação de tecido cicatricial (calo), sugere-se que o enraizamento adventício foi dado pelo processo direto. Assim como observado em Odontonema strictum, a formação de raízes adventícias, a partir das células floemáticas, também já foi descrita para outras espécies como Lycopersicum, Cucurbita e algumas variedades de Phaseolus (HARTMANN et al., 2011).

Com base na análise de variância (Tabela 1), o número de brotos por estaca foi influenciado pela interação época vs concentração de AIB. 
Tabela 1. Análise de variância para os parâmetros número de brotos por estaca (NBE), comprimento do maior broto (CMB) e da maior raiz (CMR) avaliadas para duas épocas e sua interação com três concentrações de AIB para diferentes tipos de estacas propagadas de Odontonema strictum em Seropédica, RJ, Brasil.

\begin{tabular}{lcccc}
\hline \multicolumn{1}{c}{ Fonte de Variação } & GL & NBE & CMB & CMR \\
\hline Época (EP) & 1 & $7,086^{*}$ & $67,048^{\mathrm{ns}}$ & $11,541^{\mathrm{ns}}$ \\
Tipo de Estaca (TE) & 2 & $1,358^{\mathrm{ns}}$ & $19,482^{\mathrm{ns}}$ & $2,417^{\mathrm{ns}}$ \\
Concentração (AIB) & 2 & $0,031^{\mathrm{ns}}$ & $0,332^{\mathrm{ns}}$ & $1,096^{\mathrm{ns}}$ \\
EP x TE & 2 & $1,582^{\mathrm{ns}}$ & $33,658^{*}$ & $5,232^{*}$ \\
EP x AIB & 2 & $3,506^{*}$ & $0,010^{*}$ & $1,6262^{\mathrm{ns}}$ \\
TE x AIB & 4 & $1,781^{\mathrm{ns}}$ & $0,493^{\mathrm{ns}}$ & $0,415^{\mathrm{ns}}$ \\
EP x TE x AIB & 4 & $0,408^{\mathrm{ns}}$ & $0,585^{\mathrm{ns}}$ & $0,506^{\mathrm{ns}}$ \\
Tratamento & 17 & $1,694^{\mathrm{ns}}$ & $6,926^{\mathrm{ns}}$ & $2,116^{\mathrm{ns}}$ \\
Bloco & 2 & $0,367^{\mathrm{ns}}$ & $3,766^{\mathrm{ns}}$ & $0,797^{\mathrm{ns}}$ \\
Erro & 34 & & 22,18 \\
\hline CV(\%) & \multicolumn{5}{c}{14,50} \\
* significativo ao nível de 5\% de probabilidade pelo teste F; ${ }^{\mathrm{ns}}=$ não significativo ao nível de \\
5\% de probabilidade; CV= Coeficiente de Variação $(\%)$.
\end{tabular}

Constatou-se maior número de brotos das mudas provenientes de estacas coletadas na época 2 (Inverno/Primavera), sem aplicação de AIB (Tabela 2). Observou-se que para o comprimento do maior broto as interações época vs tipo de estaca e época vs concentração de AIB tiveram influencia nas brotações. Já o comprimento da maior raiz foi influenciado significativamente somente para a interação época vs tipo de estaca
(Tabela 1). Norberto et al. (2001) verificaram maior percentual de estacas brotadas em épocas mais tardias (junho). Da mesma maneira, Zem et al. (2015) verificaram melhores resultados de brotações no inverno, sendo $78,94 \%$ de estacas brotadas. Para os demais tratamentos não houve diferença entre épocas e concentração de AIB quanto ao número de brotos por estaca.

Tabela 2. Número de brotos por estaca (NBE) submetidas às diferentes concentrações de AIB para a propagação de Odontonema strictum em duas épocas distintas, em Seropédica, RJ, Brasil.

\begin{tabular}{cccc}
\hline \multirow{2}{*}{ Fator Época } & \multicolumn{3}{c}{ Concentração AIB $\left(\mathrm{mg}^{\circ} \mathrm{L}^{-1}\right)$} \\
\cline { 2 - 4 } & 0 & 1000 & 2000 \\
\hline Época 1 (Verão/Outono) & $1,988 \mathrm{bA}$ & $2,155 \mathrm{aA}$ & $2,211 \mathrm{aA}$ \\
Época 2 (Inverno/Primavera) & $2,466 \mathrm{aA}$ & $2,255 \mathrm{aA}$ & $2,233 \mathrm{aA}$ \\
\hline
\end{tabular}

Médias seguidas pela mesma letra minúscula na coluna e maiúscula na linha, não diferem estatisticamente pelo Teste de Tukey a $5 \%$ de probabilidade. DMS = Diferença mínima significativa de 0,2646 para coluna e 0,3185 para linha.

Observou-se que para a variável comprimento do maior broto (CMB), a época 1 (Verão/Outono) mostrou-se mais favorável em relação a época 2 (Inverno/Primavera) (Tabela 3). De acordo com Fachinello et al. (2005) a influência da elevação da temperatura favorece o desenvolvimento da parte aérea. Deste modo, a época de Verão/Outono foi mais promissora para o comprimento do maior broto, quando estacas semilenhosa e lenhosa foram utilizadas. De modo geral, para ambas as épocas de coleta a utilização 
Tabela 3. Comprimento $(\mathrm{cm})$ do maior broto $(\mathrm{CMB})$ de diferentes tipos de estacas de Odontonema strictum propagadas em duas épocas distintas em Seropédica, RJ, Brasil.

\begin{tabular}{cccc}
\hline \multirow{2}{*}{ Fator Época } & \multicolumn{3}{c}{ Tipos de Estacas } \\
\cline { 2 - 4 } & Herbácea & Semilenhosa & Lenhosa \\
\hline Época 1 (Verão/Outono) & $1,058 \mathrm{aB}$ & $1,181 \mathrm{aAB}$ & $1,229 \mathrm{aA}$ \\
Época 2 Inverno/Primavera) & $0,608 \mathrm{bB}$ & $0,866 \mathrm{bA}$ & $1,029 \mathrm{bA}$ \\
\hline
\end{tabular}

Médias seguidas pela mesma letra minúscula na coluna e maiúscula na linha, não diferem estatisticamente pelo Teste de Tukey a 5\% de probabilidade. DMS = Diferença mínima significativa de 0,1384 para coluna e 0,1666 para linha

Para a característica de comprimento do maior broto (CMB), oriunda das estacas coletadas na época 1 (Verão/Outono) apresentou maior quando comparado a época 2 (Inverno/Primavera), o que resultou em diferença significativa entre todas as concentrações 0, 1000 e 2000 mg. $L^{-1}$ de AIB (Tabela 4). Desse modo, a propagação da Odontonema strictum no verão/outono pode ser uma alternativa interessante na redução de custos para o produtor, visto que, nessa época o comprimento do maior broto foi superior à época inverno/primavera independente da aplicação do fitorregulador. A propagação na época inverno/primavera mostrou-se não ser uma boa alternativa, uma vez que, mesmo com a aplicação de AIB o comprimento do maior broto foi inferior a época Verão/Outono (Tabela 4).

Tabela 4. Comprimento $(\mathrm{cm})$ do maior broto $(\mathrm{CMB})$ de estacas submetidas às diferentes concentrações de AIB para a propagação de Odontonema strictum em duas épocas distintas, em Seropédica, RJ, Brasil.

\begin{tabular}{cccc}
\hline \multirow{2}{*}{ Fator Época } & \multicolumn{3}{c}{ Concentração (AIB) mg. L ${ }^{-1}$} \\
\cline { 2 - 4 } & 0 & 1000 & 2000 \\
\hline Época 1 (Verão/Outono) & $1,177 \mathrm{aA}$ & $1,153 \mathrm{aA}$ & $1,137 \mathrm{aA}$ \\
Época 2 (Inverno/Primavera) & $0,857 \mathrm{bA}$ & $0,824 \mathrm{bA}$ & $0,822 \mathrm{bA}$ \\
\hline
\end{tabular}

Médias seguidas pela mesma letra minúscula na coluna e maiúscula na linha, não diferem estatisticamente pelo Teste de Tukey a 5\% de probabilidade. DMS = Diferença mínima significativa de 0,1384 para coluna e 0,1666 para linha.

O comprimento da maior raiz (CMR) é parâmetro importante para a formação da muda. Com base na tabela 5, verificamos que as estacas do tipo herbáceas apresentaram diferença significativa quanto à época de coleta, ou seja, quando coletas na época 1 (Verão/Outono) apresentaram maior comprimento de raiz em relação as coletadas na época 2 (Inverno/Primavera) (Tabela 5).

As demais estacas não diferiram quanto à época de coleta para a variável comprimento de maior raiz. De acordo com os resultados, para a época 2 (Inverno/Primavera) são indicadas coletas de estacas semilenhosa e lenhosa para a variável analisada. 
Tabela 5. Comprimento $(\mathrm{cm})$ da maior raiz (CMR) de estacas herbáceas, semilenhosas e lenhosas de Odontonema strictum plantadas em duas épocas distintas em Seropédica, RJ, Brasil.

\begin{tabular}{cccc}
\hline \multirow{2}{*}{ Fator Época } & \multicolumn{3}{c}{ Tipos de Estacas } \\
\cline { 2 - 4 } & Herbácea & Semilenhosa & Lenhosa \\
\hline Época 1 (Verão/Outono) & $14,100 \mathrm{aA}$ & $13,872 \mathrm{aA}$ & $13,033 \mathrm{aA}$ \\
Época 2 (Inverno/Primavera) & $8,3912 \mathrm{bB}$ & $11,784 \mathrm{aA}$ & $13,202 \mathrm{aA}$ \\
\hline
\end{tabular}

Médias seguidas pela mesma letra minúscula na coluna e maiúscula na linha, não diferem estatisticamente pelo Teste de Tukey a 5\% de probabilidade. DMS = Diferença mínima significativa de 2,6361 para coluna e 3,1726 para linha

Estacas coletadas na época 1 (Verão/Outono) apresentaram maior comprimento radicular independente da aplicação AIB. Esses resultados corroboram com o trabalho de Norberto et al. (2001) que demonstraram que o enraizamento da figueira apresentou diferença de acordo com a época do ano. Assim, a estação do outono é uma época extremamente favorável para a indução radicial em Odontonema, e não somente o Inverno, conforme citado por Lorenzi \& Souza (2001). Segundo Fachinello et al. (1995) estacas coletadas no inverno possuem maior grau de lignificação e

\section{CONCLUSÃO}

A espécie Odontonema strictum (Nees) tem grande capacidade regenerativa e pode ser considerada como de fácil enraizamento, independente da aplicação do fitorregular (AIB) e do tipo de estaca.

A espécie não apresenta dificuldade em ser propagada nas condições testadas.

\section{REFERÊNCIAS BIBLIOGRÁFICAS}

ALTAMURA, M. M. Root histogenisis in herbaceous and woody explants cultured in vitro. A critical review. Agronomie, Paris, v. 16, p. 589-602. 1996.

ALVES, E. C. Clonagem por estaquia de ramos de Dovyalis hebecarpa e Dovyalis hebecarpa x D. abissinica. 2014. 33p. Dissertação (Mestrado em Produção Vegetal) - Universidade Estadual Paulista, Jaboticabal, 2014. tendem a enraizar menos, todavia, parece não acontecer com as plantas de Odontonema strictum que apresentaram $100 \%$ de enraizamento e o comprimento da maior raiz favorável para estacas do tipo semilenhosa e lenhosa, mesmo na época mais fria.

As raízes adventícias não encontram barreiras estruturais quando da utilização de estacas herbáceas, pois os tecidos apresentam parede celular primária e não lignificada, o que pode explicar em parte a facilidade de enraizamento (WHITE \& LOVELL, 1984; HARTMANN et al., 2010).

No entanto, a época de coleta de estadas de Odontonema strictum (Nees) Verão/Outono mostrou-se mais adequada devido ao melhor desenvolvimento das mudas.

AMARAL, G. C.; BRITO, L. P. D. S.; AVELINO, R. C.; SILVA JÚNIOR, J. V. D.; BECKMANN-CAVALCANTE, M. Z.; CAVALCANTE, Í. H. L. Produção de mudas de Duranta repens L. pelo processo de estaquia. Revista de Ciências Agrárias, v. 35, n. 1, p. 134-142, 2012.

BLAZICH, F. A. Chemicals and formulations used to promote adventitious rooting. In: DAVIES, T. D.; HAISSIG, B. E.; SANKHLA, N. (Org.). Adventitious 
root formation in cuttings. Portland: Dioscorides Press, 1987. p. 132-149. (Advances in Plant Sciences Series, 2).

FACHINELLO, J. C.; HOFFMANN, A.; NACHTIGAL, J. C. Propagação de plantas frutíferas de clima temperado. Pelotas: UFPEL, 1995. 179p.

FACHINELLO, J. C.; HOFFMANN, A.; NACHTIGAL, J. C. Propagação de plantas frutíferas. Brasília: EMBRAPA, 2005. 221p.

HARTMANN, H. T.; KESTER, D. E.; DAVIES JR., F. T.; GENEVE, R. L. Plant propagation: principles and practices. 8th ed. New Jersey: Englewood Clipps, 2010. 928p.

HARTMANN, H. T.; KESTER, D. E.; DAVIES JR., F. T.; GENEVE, R. L. Plant propagation: principles and practices. 8th ed. New Jersey: PrenticeHall, 2011. $915 \mathrm{p}$.

LAFETÁ, B. O.; MATOS, M. P.; LAGE, P.; FERRARO, A. C.; PENIDO, T. M. A. Ácido indol-3-butírico (AIB) no enraizamento de estacas de fedegoso gigante. Pesquisa Florestal Brasileira, v. 36, n. 88, p. 489-496, 2016.

LARCHER, L.; BOEGER, M. R. T. Anatomia foliar de Odontonema strictum (Nees) O. Kuntze (Acanthaceae). Biotemas, v. 19, n. 4, p. 23-31, 2006.

LIMA, M. R. Estratégias de propagação para espécies subarbustivas de Acanthaceae Juss. com potencial ornamental. 2012, 165f. Dissertação (Mestrado em Botânica) - Universidade de Brasília, Brasília, 2012.

LORENZI, H.; SOUZA, H. M. Plantas Ornamentais no Brasil: arbustos, herbáceas e trepadeiras. Instituto Plantarum. 3. Edição. Nova Odessa, São Paulo, 2001.
NEGISHI, N.; NAKAHAMA, K.; URATA, N.; KOJIMA, M.; SAKAKIBARA, H.; KAWAOKA, A. Hormone level analysis on adventitious root formation in Eucalyptus globulus. New Forests, v.45, p.577-587, 2014.

NERY, F. S. G.; ZUFFELLATO-RIBAS, K. C.; KOEHLER, H. S. Enraizamento de Psychotria nuda (Cham. \& Schltdl.) Wawra (Rubiaceae) nas quatro estações do ano. Ciência Florestal 24: 243-250. 2014.

NORBERTO, P. M.; CHALFUN, N. N. J.; PASQUAL, M.; VEIGA, R. D.; PEREIRA, G. E.; MOTA, J. H. Efeito da época de estaquia e do AIB no enraizamento de estacas de figueira (Ficus carica L.). Ciência e Agrotecnologia, v. 25, n. 3, p. 533-541, 2001.

PROFICE, S. R.; KAMEYAMA, C.; CÔRTES, A. L. A.; BRAZ, D. M.; INDRIUNAS, A.; VILAR, T.; PESSOA, C.; EZCURRA, C.; WASSHAUSEN, D. Acanthaceae in Lista de Espécies da Flora do Brasil. Jardim Botânico do Rio de Janeiro. Disponível em: <http://floradobrasil.jbrj.gov.br/jabot/flora dobrasil/FB33>. Acesso em: 31 Jul. 2017.

SANTOS, L. W.; COELHO, M. D. F.; DOMBROSKI, J. L.; AZEVEDO, R. A. Propagação vegetativa de mulungu (Erythrina velutina Willd. - Fabaceae). Revista Brasileira de Ciências Agrárias, v. 9, n. 3, p. 420-426, 2014.

SILVA, F. A. S. (2016). Assistat Versão 7.7. http://www.assistat.com. 24 Set. 2017.

XAVIER, A. Silvicultura clonal: princípios e técnicas. 2. ed. Viçosa, MG: Ed. da UFV, 2013. 279 p.

WHITE, J.; LOVELL, P. H. The anatomy of root initiation in cuttings of Griselinia littoralis and Griselinia lucida. Annals of Botany, London, v. 54, p. 7-20. 1984.

ZEM, L. M.; ZUFFELLATO-RIBAS, K. C.; RADOMSKI, M. I.; KOEHLER, H. S. 
Enraizamento de estacas semilenhosas de cataia coletadas em quatro estações. Ciência Rural, 45(10), 1815-1818, 2015.

ZOTTELE, L.; AOYAMA, E. M. Morfoanatomia e enraizamento de estacas caulinares de Justicia wasshauseniana Profice (Acanthaceae). Natureza Online, 12:179-184, 2014.

ZUFFELLATO-RIBAS, C. K.; BOEGER, M. R. T.; BONA, C.; PAES, E. DA G. B.; PIMENTA, A. C.; MASUDA, E. T. Enraizamento e morfoanatomia de estacas caulinares de Odontonema strictum (Nees) O. Kuntze (Acanthaceae). Revista Horticultura Ornamental, v. 61. p. 11:57. 2005. 